\title{
E. coli bacteremia in comparison to $K$. pneumoniae bacteremia: influence of pathogen species and ESBL production on 7-day mortality
}

\author{
R. Leistner ${ }^{1,2^{*}}$, A. Bloch $^{3}$, P. Gastmeier ${ }^{1,2}$ and F. Schwab ${ }^{1,2}$
}

\begin{abstract}
In a previous study, we demonstrated prolonged length of hospital stay in cases of extended-spectrum beta-lactamase (ESBL)-positive K. pneumoniae bacteremia compared to bacteremia cases due to E. coli (ESBL-positive and -negative) and ESBL-negative K. pneumoniae. The overall mortality was significantly higher in bacteremia cases resulting from ESBL-positive pathogens but also in K. pneumoniae cases disregarding ESBL-production. In order to examine whether pathogen species rather than multidrug resistance might affect mortality risk, we reanalyzed our dataset that includes 1.851 cases of bacteremia.
\end{abstract}

Keywords: ESBL, Bacteremia, Sepsis, K. pneumoniae, E. coli, Enterobacteriaceae, Mortality

\section{Background}

The incidence of infections associated with multidrugresistant Gram-negative organisms like extendedspectrum beta-lactamase producing Enterobacteriaceae (ESBL-E) is growing in Germany [1]. These infections, according to reports, result in increased mortality and an elevated financial burden for hospitals and health care systems [2]. In 2014, we published the results of a study on the costs of bloodstream infections (BSI) with ESBL-E and length of resulting hospital stays [3]. Our data showed that in particular $K$. pneumoniae was related to prolonged length of stays and increased hospital costs regardless the detection of ESBL production. We furthermore observed a significantly increased overall mortality associated with ESBL-positive pathogens $(25.0 \%$ vs. $19.0 \%, p$-value $=0.028)$. However, this difference in mortality was also observed in $K$. pneumoniae cases compared to $E$. coli cases without considering ESBL-production $(25.0 \%$ vs. $18.5 \%, p=0.006)$. This

\footnotetext{
* Correspondence: rasmus.leistner@charite.de

${ }^{1}$ Institute of Hygiene and Environmental Medicine, Charité

Universitätsmedizin Berlin, Hindenburgdamm 27, 12203 Berlin, Germany

${ }^{2}$ National Reference Center for the Surveillance of Nosocomial Infections,

Berlin, Germany

Full list of author information is available at the end of the article
}

observation posed the question whether the pathogen species or multidrug resistance had a greater influence on the mortality rate.

\section{Methods}

We reanalyzed the dataset to examine risk factors for mortality including pathogen species and ESBL production. All definitions remained the same from the previous publication with the exception of mortality rate. In order to detect mortality rates attributable to the bloodstream infection (BSI-attributable mortality), we focused on the 7-day mortality rate after BSI onset. All other definitions were following the original publication. The median and the interquartile range (IQR) were calculated for continuous parameters, numbers and percentage were calculated for binary parameters. Differences between deceased patients and those who survived were tested using the Wilcoxon rank sum test for continuous variables and the Chi square test for binary variables. A $p$-value $<0.05$ was considered statistically significant. In the multivariable analysis, Coxproportional hazard regression analysis was performed to investigate the risk factors for mortality $\leq 7$ days after BSI onset (BSI-attributable mortality). We calculated adjusted hazard ratios (HR) for pathogen species and ESBLpositivity. Model building strategy was step-wise forward 
with a $p$-value $<.05$ for including a variable in the model. All parameters with a $p$-value $<0.1$ in the univariable analysis were considered in the multivariable analysis, and the interaction between pathogen species and ESBL-positivity were included in all multivariable models. Underlying comorbidities were assessed as in the original publication. In order to enable a comparison between the risk factors for BSI-attributable mortality (7-day mortality) and in-hospital mortality, the analysis was repeated for the latter using the same parameters and statistical method. All analyses were performed using SPSS (IBM SPSS statistics, Somer, NY, USA) and SAS (SAS Institute, Cary, NC, USA).

\section{Results}

Overall $8.7 \%(n=161)$ of the patients were deceased within seven days of developing a bloodstream infection whereas $n=205(11.1 \%)$ patients died at a later point in time during their hospital stay (Table 1). In the univariable analysis, patients who died within the 7 days after BSI onset were significantly older compared to the 7-day survivors. However, this was not observed concerning overall in-hospital mortality. With respect to the 7-day mortality, there was no statistical significant difference observed concerning ESBL-production or pathogen species. Furthermore, the following parameter showed significantly increased risk for overall in-hospital mortality but not for 7-day mortality: polymicrobial BSI, male sex, hospital onset, cerebrovascular disease, lung disease and cancer/immunological disease.

In the multivariable analysis, independently associated factors with 7-day mortality were renal disease, liver disease, cancer /immunological disease and heart disease (Table 2). No effect was observed concerning neither pathogen species nor ESBL-production. For overall in-hospital mortality, a similar risk profile could be observed concerning underlying diseases.

Table 1 Univariate analysis of 7 days mortality in patients with extended-spectrum beta-lactamase (ESBL)-positive or -negative E. coli and K. pneumoniae bloodstream infection (during hospitalization)

\begin{tabular}{|c|c|c|c|c|c|c|c|c|}
\hline \multirow[t]{2}{*}{ Parameter } & $\begin{array}{l}\text { Survived until } \\
7 \text { days after BSI }\end{array}$ & $\begin{array}{l}\text { Died within } \\
7 \text { days after BSI }\end{array}$ & $\begin{array}{l}\text { 7-days } \\
\text { Mortality }\end{array}$ & $P$-value & \multirow{2}{*}{$\begin{array}{l}\text { Survived/ discharged } \\
\text { after BSI } \\
\text { Number (\%) }\end{array}$} & $\begin{array}{l}\text { Died in-hospital } \\
\text { after BSI }\end{array}$ & \multirow[t]{2}{*}{$\begin{array}{l}\text { In-hospital } \\
\text { Mortality }\end{array}$} & \multirow[t]{2}{*}{$P$-value } \\
\hline & Number (\%) & Number (\%) & & & & Number (\%) & & \\
\hline Patients & $1.690(100 \%)$ & $161(100 \%)$ & $8.7 \%$ & & 1485 (100\%) & 366 (100 \%) & $19.8 \%$ & \\
\hline K. pneumoniae & 319 (18.9 \%) & $33(20.5 \%)$ & $9.4 \%$ & 0.616 & 264 (17.8\%) & 88 (24.0\%) & $25.0 \%$ & 0.006 \\
\hline E. coli & 1371 (81.1%) & 128 (79.5 \%) & $8.5 \%$ & & 1221 (82.2 \%) & 278 (76.0 \%) & $18.5 \%$ & \\
\hline ESBL-positive & 219 (13.0 \%) & 25 (15.5 \%) & $10.2 \%$ & 0.357 & $183(12.3 \%)$ & 61 (16.7\%) & $25.0 \%$ & 0.028 \\
\hline Hospital mortality & 205 (12.1 \%) & 161 (100.0\%) & $44.0 \%$ & $<0.001$ & - & 366 (100.0 \%) & $100.0 \%$ & n.a. \\
\hline Polymicrobial & 198 (11.7 \%) & 27 (16.8 \%) & $12.0 \%$ & $0.061^{*}$ & 160 (10.8 \%) & 65 (17.8 \%) & $28.9 \%$ & $<0.001^{*}$ \\
\hline Age (years) ${ }^{a}$ & $65(52-73)^{a}$ & $67(57-76)^{\mathrm{a}}$ & n.a. & $0.019^{*}$ & $65(52-73)^{\mathrm{a}}$ & $66(54-74)^{\mathrm{a}}$ & n.a. & $0.134^{*}$ \\
\hline Male & 929 (55.0 \%) & 93 (57.8 \%) & $9.1 \%$ & 0.496 & 799 (53.8 \%) & 223 (60.9 \%) & $21.8 \%$ & 0.014 \\
\hline Hospital onset & 746 (44.1 \%) & $84(52.2 \%)$ & $10.1 \%$ & $0.050^{*}$ & 612 (41.2 \%) & 218 (59.6 \%) & $26.3 \%$ & $<0.001^{*}$ \\
\hline ICU stay & 1.072 (63.4 \%) & 125 (77.6 \%) & $10.4 \%$ & $<0.001 *$ & $896(60.3 \%)$ & 301 (82.2 \%) & $25.1 \%$ & $<0.001 *$ \\
\hline Charlson comorbidity index ${ }^{a}$ & $5(3-8)^{a}$ & $8(6-10)^{a}$ & n.a. & $<0.001$ & $5(3-8)^{a}$ & $8(6-10)^{a}$ & n.a. & $<0.001$ \\
\hline Heart disease & $275(16.3 \%)$ & 47 (29.2 \%) & $14.6 \%$ & $<0.001^{*}$ & $215(14.5 \%)$ & $107(29.2 \%)$ & $33.2 \%$ & $<0.001^{*}$ \\
\hline Cerebrovascular disease & $243(14.4 \%)$ & $31(19.3 \%)$ & $11.3 \%$ & $0.096^{*}$ & $202(13.6 \%)$ & $72(19.7 \%)$ & $26.3 \%$ & $0.003^{*}$ \\
\hline Neurologic disease & $123(7.3 \%)$ & $11(6.8 \%)$ & $8.2 \%$ & 0.835 & $112(7.5 \%)$ & $22(6.0 \%)$ & $16.4 \%$ & 0.311 \\
\hline Lung disease & $218(12.9 \%)$ & $24(14.9 \%)$ & $9.9 \%$ & 0.470 & $181(12.2 \%)$ & $61(16.7 \%)$ & $25.2 \%$ & 0.023 \\
\hline Gastrointestinal disease & $53(3.1 \%)$ & $12(7.5 \%)$ & $18.5 \%$ & $0.004^{*}$ & $36(2.4 \%)$ & $29(7.9 \%)$ & $44.6 \%$ & $<0.001^{*}$ \\
\hline Rheumatic disease & $50(3.0 \%)$ & $2(1.2 \%)$ & $3.8 \%$ & 0.208 & $44(3.0 \%)$ & $8(2.2 \%)$ & $15.4 \%$ & 0.420 \\
\hline Liver disease & $258(15.3 \%)$ & $53(32.9 \%)$ & $17.0 \%$ & $<0.001 *$ & 180 (12.1\%) & $131(35.8 \%)$ & $42.1 \%$ & $<0.001^{*}$ \\
\hline Diabetes & $422(25.0 \%)$ & $48(29.8 \%)$ & $10.2 \%$ & 0.177 & $366(24.6 \%)$ & $104(28.4 \%)$ & $22.1 \%$ & 0.138 \\
\hline Renal disease & 711 (42.1 \%) & $115(71.4 \%)$ & $13.9 \%$ & $<0.001 *$ & $565(38.0 \%)$ & $261(71.3 \%)$ & $31.6 \%$ & $<0.001 *$ \\
\hline Cancer/immunological disease & $672(39.8 \%)$ & 75 (46.6\%) & $10.0 \%$ & $0.092^{*}$ & $571(38.5 \%)$ & $176(48.1 \%)$ & $23.6 \%$ & $0.001^{*}$ \\
\hline
\end{tabular}

BSI bloodstream infection, LOS length of stay, N.a. not applicable

* Included in the multivariable Cox-proportional hazard regression

${ }^{a}$ Continuous parameter displayed as median (interquartile range)

$P$-values $<0.05$ were considered statistically significant 
Table 2 Multivariable Cox-proportional hazard regression of risk factors for 7-day mortality and hospital mortality after BSI with ESBL-positive or -negative E. coli and K. pneumoniae

\begin{tabular}{|c|c|c|c|c|c|c|c|}
\hline \multirow[t]{2}{*}{ Parameter } & \multirow[t]{2}{*}{ Parameter/ category } & \multicolumn{3}{|c|}{ 7-days mortality (stepwise) } & \multicolumn{3}{|c|}{ In-hospital mortality ${ }^{a}$} \\
\hline & & $\mathrm{HR}$ & $\mathrm{Cl} 95$ & $P$-value & $\mathrm{HR}$ & $\mathrm{C} 195$ & $P$-value \\
\hline \multirow{4}{*}{$\begin{array}{l}\text { Interaction effect between pathogen } \\
\text { species and ESBL-production }\end{array}$} & E. coli ESBL-negative & $1=$ Reference & & 0.947 & $1=$ Reference & & 0.084 \\
\hline & E. coli ESBL-positive & 1.16 & $0.70-1.90$ & 0.571 & 1.22 & $0.88-1.68$ & 0.228 \\
\hline & K. pneumoniae ESBL-negative & 0.98 & $0.64-1.50$ & 0.926 & 1.39 & $1.07-1.82$ & 0.015 \\
\hline & K. pneumoniae ESBL-positive & 1.05 & $0.49-2.27$ & 0.894 & 1.01 & $0.60-1.67$ & 0.983 \\
\hline \multirow[t]{4}{*}{ Comorbidities } & Heart disease & 1.55 & $1.09-2.21$ & 0.014 & 1.23 & $0.97-1.56$ & 0.087 \\
\hline & Liver disease & 1.96 & $1.40-2.74$ & $<0.001$ & 1.85 & $1.48-2.30$ & $<0.001$ \\
\hline & Renal disease & 2.86 & $1.99-4.10$ & $<0.001$ & 2.32 & $1.82-2.95$ & $<0.001$ \\
\hline & Cancer/ immunological disease & 1.66 & $1.21-2.28$ & 0.002 & 1.58 & $1.28-1.95$ & $<0.001$ \\
\hline
\end{tabular}

ESBL extended-spectrum beta-lactamase, HR hazard ratio, C19595\% confidence interval, N.s. not significant

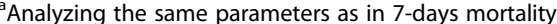

$P$-values $<0.05$ were considered statistically significant

Here, BSI with ESBL-negative $K$. pneumoniae was found to be an independent risk factor for overall inhospital mortality.

\section{Discussion}

In earlier studies, ESBL-positive pathogens causing infections were associated with increased mortality [2]. However, recent studies have cast doubt on this general assumption and showed a lack of sufficiently controlled studies especially with respect to antimicrobial treatment $[4,5]$. Unfortunately, we do not have sufficient data on antimicrobial treatment and are unable to examine this assumption. Especially carbapenem resistance poses a serious threat, as carbapenems are the most important reserve substances for these infections [6]. However, our cohort was comprised of only two cases resulting from carbapenem-resistant organisms.

In the original publication, $K$. pneumoniae cases were associated with a significantly higher comorbidity index ( 6 vs. $5, p=0.001$ ). K. pneumoniae BSIs were more often associated with the detection of other organisms in the same blood culture $(24.4 \%$ vs. $9.9 \%, p \leq 0.001)$ and they occurred later than the respective $E$. coli BSIs (hospital day 6 vs. $1, p \leq 0.001)$. These observations indicate epidemiological and pathophysiological differences between both groups that we do not yet entirely understand.

In the analysis at hand, we observed severe comorbidities, like renal disease, liver disease or cancer to be the only independently associated risk factors for BSIattributable mortality. In contrast, ESBL-negative K. pneumoniae (in addition to comorbidities) was independently associated with in-hospital mortality. We see this as the result of an unmeasured confounder that is associated with increased risk of mortality in the aftermath of survival from a K. pneumoniae BSI.

This analysis has limitations. Our data lacks information on antimicrobial therapy, which could provide further information. However, the patients were treated following current sepsis guidelines. The guidelines do not differentiate between $K$. pneumoniae and E. coli and therefore render a systematical therapeutic difference unlikely. Data on source of BSI and on the severity of disease (e.g. sepsis, septic shock) were not sufficiently available. Therefore, we could not adjust for the effect of these potential confounders.

\section{Conclusions}

ESBL-E BSI-attributable mortality was influenced neither by pathogen species nor by ESBL-production. However, we observed epidemiological differences between patients infected with $K$. pneumoniae or E.coli that lead to an increased in-hospital mortality, not attributable to the BSI episode. Both pathogens are the most commonly found representatives of ESBL-producing bacteria in clinical isolates. Hence, it is of paramount importance to understand the factors that determine the course of infection and the overall outcome. Thus, further well-designed studies of epidemiological and pathophysiological differences between $K$. pneumoniae and $E$. coli -infections are necessary.

\section{Abbreviations}

BSI: Bloodstream infections; E. coli: Escherichia coli; ESBL-E: Extended-spectrum beta-lactamase producing Enterobacteriaceae; HR: Hazard ratio;

IQR: Interquartile range; K. pneumoniae: Klebsiella pneumoniae

\section{Acknowledgment}

Not applicable.

Funding

$\mathrm{RL}$ is partly funded by grants from the Federal Ministry of Education and Health, Germany [No. 01Kl1013H].

Availability of data and materials

The complete anonymized dataset is available from the corresponding author upon request.

Authors' contributions

$P G$ and $R L$ developed the idea, $R L$ and FS drafted the manuscript. FS developed the mathematical model and performed the statistical analysis. All authors read and approved the final manuscript. 


\section{Competing interests}

The authors declare that they have no competing interests.

\section{Consent for publication}

Not applicable.

\section{Ethics approval and consent to participate}

The approval of the ethics committee of Charité Universitätsmedizin Berlin

for this study was obtained previously (process number EA4/031/11).

\section{Author details}

${ }^{1}$ Institute of Hygiene and Environmental Medicine, Charité

Universitätsmedizin Berlin, Hindenburgdamm 27, 12203 Berlin, Germany.

${ }^{2}$ National Reference Center for the Surveillance of Nosocomial Infections, Berlin, Germany. ${ }^{3}$ Department of Medical and Financial Controlling, Charité

Universitätsmedizin Berlin, Berlin, Germany.

Received: 30 May 2016 Accepted: 3 October 2016

Published online: 19 October 2016

\section{References}

1. Leistner R, Schroder C, Geffers C, Breier AC, Gastmeier P, Behnke M. Regional distribution of nosocomial infections due to ESBL-positive Enterobacteriaceae in Germany: data from the German National Reference Center for the Surveillance of Nosocomial Infections (KISS). Clin Microbiol Infect. 2015;21(3):255.e1-5.

2. Shorr AF. Review of studies of the impact on Gram-negative bacterial resistance on outcomes in the intensive care unit. Crit Care Med. 2009;37(4):1463-9.

3. Leistner R, Gurntke S, Sakellariou C, Denkel LA, Bloch A, Gastmeier P, et al. Bloodstream infection due to extended-spectrum beta-lactamase (ESBL)positive K. pneumoniae and E. coli: an analysis of the disease burden in a large cohort. Infection. 2014;42(6):991-7.

4. Rottier WC, Ammerlaan HS, Bonten MJ. Effects of confounders and intermediates on the association of bacteraemia caused by extendedspectrum beta-lactamase-producing Enterobacteriaceae and patient outcome: a meta-analysis. J Antimicrob Chemother. 2012;67(6):1311-20.

5. Schwaber MJ, Carmeli Y. Mortality and delay in effective therapy associated with extended-spectrum beta-lactamase production in Enterobacteriaceae bacteraemia: a systematic review and meta-analysis. J Antimicrob Chemother. 2007;60(5):913-20.

6. Marston HD, Dixon DM, Knisely JM, Palmore TN, Fauci AS. Antimicrobial resistance. JAMA. 2016:316(11):1193-204.

\section{Submit your next manuscript to BioMed Central and we will help you at every step:}

- We accept pre-submission inquiries

- Our selector tool helps you to find the most relevant journal

- We provide round the clock customer support

- Convenient online submission

- Thorough peer review

- Inclusion in PubMed and all major indexing services

- Maximum visibility for your research

Submit your manuscript at www.biomedcentral.com/submit
Biomed Central 